\title{
Epidemiological Aspects of Metastatic Relapse of Breast Cancer in an African Context
}

\author{
Jean Marc Dia ${ }^{1}$, Corneille Saki ${ }^{1}$, Oyeladé Mouhideen${ }^{1}$, Eric Bohoussou ${ }^{1}$, Moctar Touré2 , \\ Gerard Okon'1, Privat Guié1, Simplice Anongba ${ }^{1}$
}

\begin{abstract}
${ }^{1}$ Gynecology Department of the University and Hospital Center of Treichville (CHUT), Abidjan, Côte d'Ivoire ${ }^{2}$ Cancerology Department of the University and Hospital Center of Treichville (CHUT), Abidjan, Côte d'Ivoire Email: ^jmlaminedia@yahoo.fr
\end{abstract}

How to cite this paper: Dia, J.M., Saki, C., Mouhideen, O., Bohoussou, E., Touré, M., Okon, G., Guié, P. and Anongba, S. (2017) Epidemiological Aspects of Metastatic Relapse of Breast Cancer in an African Context. Open Journal of Obstetrics and Gynecology, 7, 552-561.

https://doi.org/10.4236/ojog.2017.75058

Received: March 29, 2017

Accepted: May 22, 2017

Published: May 25, 2017

Copyright $\odot 2017$ by authors and Scientific Research Publishing Inc. This work is licensed under the Creative Commons Attribution International License (CC BY 4.0).

http://creativecommons.org/licenses/by/4.0/

\begin{abstract}
Objectives: This study aimed to describe the epidemiological characteristics of metastatic relapse in breast cancer at the University and Hospital Center of Treichville. Methodology: This is a cohort and retrospective study conducted from January 2000 to December 2015 on 178 patients with metastaticrelapse in breast cancer. Results: The prevalence of metastatic relapses was $49 \%$ and the patients had an average age of 53.4 years and among them, $91.6 \%$ received school education and $88.2 \%$ did not have a high socioeconomic level. The majority of initial tumors were in Stage III (47.8\%), SBR III (47.2\%), High Ki 67 (46.5\%), Negative RH (79.3\%), and HER2 negative (58\%). Metastases were generally unique $(62.9 \%)$, dominated by bone sites (36.6\%), with an average occurrencedelay of 2.4 years. After the occurrence of metastases, the cumulative survival rate was $5 \%$ at 3 years, and nil at 5 years. Conclusion: Metastatic relapses were common with poor prognosis.
\end{abstract}

\section{Keywords}

Breast Cancer, Risk Factors, Metastatic Relapses

\section{Introduction}

Breast cancer is the first woman cancer in Côte d'Ivoire as in many countries of the world [1] [2], and its prognosis is closely related to the occurrence of metastases. Also after the curative treatment of nonmetastatic forms, surveillance must be rigorous in order to quickly take care of the locoregional and metastatic relapses that could occur. ASCO (American Society of Clinical Oncology) recommends for this purpose a clinical monitoring based on the interrogation and clinical examination every 4 months for 3 years, then every 6 months for the next 2 years, then once per year for the rest of life [3]. Regarding the paraclinical 
check up, only mammography and breast ultrasound should be performed annually, and other tests (chest radiograph, tumor markers, abdominal-pelvic ultrasound, bone scan...) will be proposed only in case of complaint signs [4].

In developed countries, breast cancer management is done earlier, and metastatic relapses are generally estimated at less than $20 \%$ in ten years [5] [6] [7]. On the other hand, in developing countries, where there is no breast cancer screening program, the management of non-metastatic tumors is delayed and exposes patients to high risk of metastatic relapse after initial treatment. Yet there are few publications on metastatic relapses in African literature. This study aims to describe the epidemiological characteristics of metastatic relapses observed in an African context.

\section{Methodology}

This is a cohort and retrospective study from January 2000 to December 2015 (15 years) in the gynecology department of the University and Hospital Center of Treichville (CHUT). It involved patients who underwent a curative radical surgery for non-metastatic invasive breast cancer in that department between January 2000 and December 2010 and followed until December 2015. These patients with non-metastatic invasive breast cancer have all initially benefited from locoregional treatment and systemic treatment. The locoregional treatment consisted of a total mastectomy according to Patey with axillary node dissection, in the absence of radiotherapy and sentinel lymph node biopsy. Concerning systemic treatment, an adjuvant chemotherapy was performed in all patients, and only patients atclinicalstage II and III received a neoadjuvant chemotherapy (same protocol) before surgery. At the end of the treatment and outside of any new event, the patients are followed according to ASCO recommendations.

All patients who experienced metastatic relapse of breast cancer during follow-up after initial treatment were included in the study. Patients operated outside the department, and those with breast cancer initially metastatic at initial diagnosis, were not included in the study. Data were collected on a survey sheet from patient records, chemotherapy registers, and pathological anatomyrecords. The sample included 178 patients in whom the information was collected on a standard survey form. The parameters studied were the socio demographic characteristics, the characteristics of the initial tumor, the characteristics of metastases, and survival after metastatic relapse.The analyzes were done by the Word software, Excel, Epi info and the statistical tests used were the calculations of averages and frequencies.

\section{Results}

\subsection{Epidemiological Characteristics}

\section{- Frequency of Metastases}

From 2000 to 2010, 363 patients underwent a curative radical breast cancer surgery and during surveillance until 2015, 178 patients (49\%) developed a metastasis and 185 patients (51\%) were lost of sight before the onset of meta- 
stasis. The average duration of follow-up was 3 years 7 months (extremes 9 months - 7 years 3 months) and the cumulative survival without metastasis was $60 \%$ at 3 years and $43 \%$ at 5 years.

- Socio-demographiccharacteristics of patientswho developped metastatic reelapses

Patients had an average age of 53.4 years (extremes 38 - 74), among them $62.4 \%$ were over 50 years of age, $91.6 \%$ received school education, and $88.2 \%$ did not have a high socio-economic level.

\subsection{Characteristics of the Initial Tumor}

Immunohistochemical syudy was performed only in 58 patients $(32.6 \%)$, thus determining the status of the hormonal receptors, the $\mathrm{Ki} 67$ index and the overexpression of HER2, in the initial tumor.

\subsection{Characteristics of Metastases}

- Sites of metastases

- Chronology of occurrence of metastases

The average delay of the occurrence of metastases was 2.4 years (extremes: 8 months - 7 years 6 months).

- Survival aftermetastatic relapses

The cumulative survival rate was $5 \%$ at 3 years and nil at 5 years.

\section{Discussion}

\subsection{Epidemiological Characteristics}

\section{- Frequencyof metastases}

Metastatic relapses were frequent in the study population (49\%), with a cumulative survival rate without metastasis which was $60 \%$ at 3 years (Figure 1).

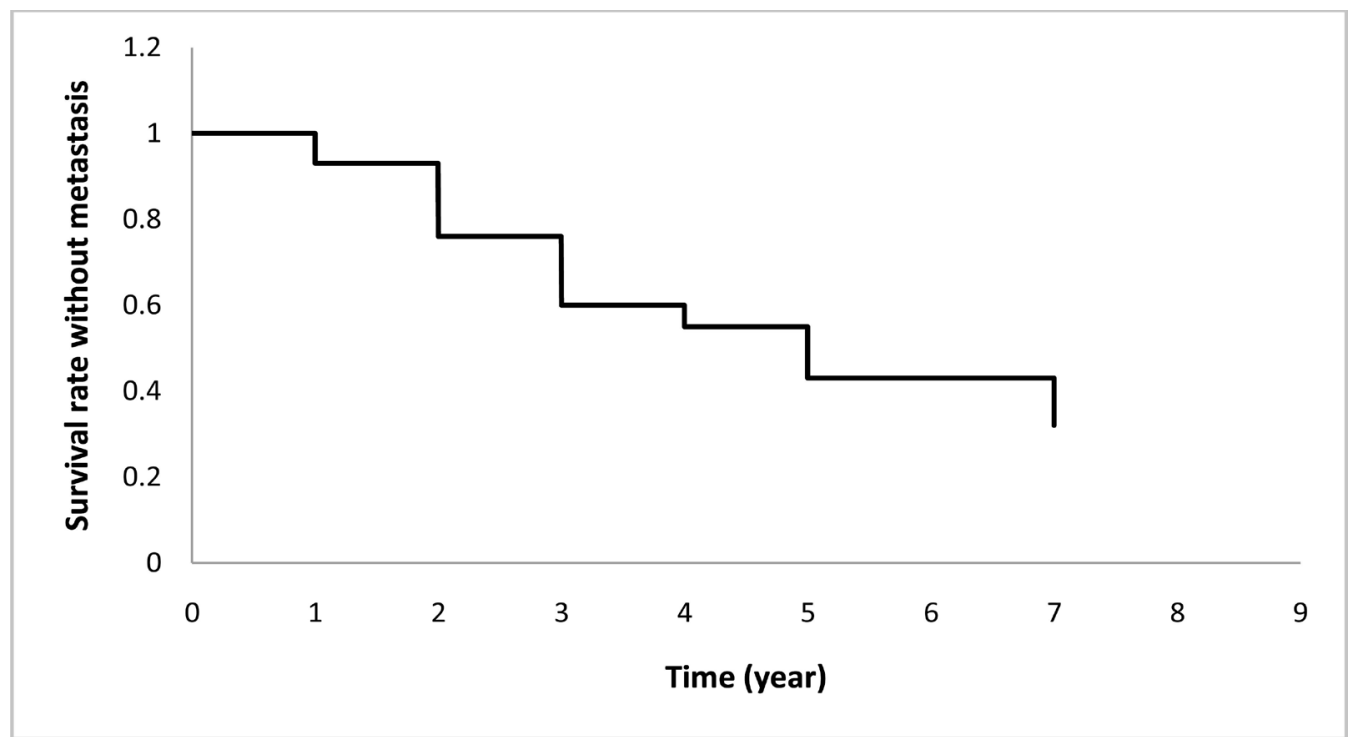

Figure 1. Survival curve without metastatic relapses of patients who underwent a curative radical surgery for invasive breast cancer from 2000 to 2010 . 
And this frequency appears to be underestimated given the high rate of loss of sight observed (51\%). In the African literature no articles were foundon the frequency of metastatic relapses. On the other hand, in developed countries where breast cancer management is done earlier with a better technical equipment, metastatic relapses are generally less frequent, estimated at less than $20 \%$ in ten years [5] [6] [7]. However, it is important to relativize these figures, because even in these developed countries, when the managment is late (clinical stage III), the rates of metastatic relapse after mastectomy are high, over $50 \%$ in 10 years [8].

- Age

The patients of this study had an average age of 53.4 years, and the majority (62.4\%) were over 50 years of age (Table 1). In the literature, it is reported that metastatic relapses are more common in women over 50 years of age, and locoregional relapses more frequent in younger women [9] [10]. Menopausal status may affect the occurrence of these metastases, but the retrospective component of this study did not allow to explore this parameter.

\section{- School level}

The majority ofthe study patients were educated (91.6\%) and had a sufficient level of education (secondary or higher) to understand the value of breast cancer screening (Table 1). This screening would have allowed the primary lesion to be managed at earlier stages in order to limit the risk of metastatic relapse. But the absence of screening programs remains a reality in the developing countries, so

Table 1. Distribution of patients according to their socio-demographic characteristics.

\begin{tabular}{ccc}
\hline Sociodemographic characteristics & Population & Frequency (\%) \\
\hline Age (years) & 8 & 4.5 \\
$<40$ years & 59 & 33.1 \\
$40-50$ & 63 & 35.4 \\
$50-60$ & 48 & 27 \\
$>60$ & 178 & 100 \\
Total & & \\
Level of study & 15 & 8.4 \\
- Non educated & 31 & 17.4 \\
- Primary & 61 & 34.3 \\
- Secondary & 71 & 39.9 \\
- High school & 178 & 100 \\
- Total & & 100 \\
Socio-economic level & 13 & 7.3 \\
- Low & 144 & 80.9 \\
- Middle & 21 & 11.8 \\
- High & 178 & 100 \\
- Total & &
\end{tabular}


that the notion of screening is unknown to the population. In a study conducted in Côte d'Ivoire on women with secondary school education, Guié found that only $21 \%$ of women over the age of 50 had already been screened for breast cancer and in $42.1 \%$ of cases that screening went back to more than 4 years [11].

\section{- Socio-economicallevel}

Table 1 also shows that patients did not generally have a high socio-economic level $(88.2 \%)$, constituting a real obstacle for the management of their disease (both the primary tumor and the metastasis). In the developing country the management of cancers is expensive, and remains the responsibility of the patients because there is no social policy of health insurance. Toure found that the lack of financial means was causing delayed breast cancer diagnosis in 36\% of the cases in the ivoirian context [1].

\subsection{Characteristics of the Initial Tumor}

\section{- Histological type of initial tumor}

In this study, $68.5 \%$ of patients had an invasive ductal carcinoma tumor, compared with $31.4 \%$ of invasive lobular carcinoma (Table 2). However, it is proved that the histological type has no influence on prognosis because all invasive cancers have the same prognosis [12] [13].

\section{- Clinical stage of the initial tumor}

The relationship between the advanced stage of the primary tumor and the occurrence of metastatic relapse has been confirmed in various studies [14] [15]. And in this study, the majority of patients $(82.6 \%)$ had a primary tumor at a locally advanced stage (Stage II or III) and therefore had a high risk of metastatic relapse (Table 2). Touré made the same observation in his study and was able to demonstrate that almost $80 \%$ of the patients consulted belatedly because of the lack of financial means, the use of traditional medication, and diagnostic errors.

\section{- Histological prognostic factors.}

Like the initial clinical stage of the disease, the usual histological prognostic factors condition the risk of metastatic relapse, especially in the first 5 years following the initial curative treatment [16]. Thus, the high grade SBRinfluences the frequence and early occurrenceof metastatic relapses with high mortality rate [17] [18]. In this series (Table 2), it was also found that metastatic relapses were more important in the highest grade: grade III (47.2\%), II (35.4\%) and I (17.4\%).

For other prognostic factors diagnosed by immunohistochemistry (hormonal receptors, Ki 67, HER2), they were investigated in only 58 patients (32.6\%) because the laboratories were not equipped to carry out this examination during the Period of study. These tests were carried out abroad (France) at costs beyond the reach of the majority of patients. However, in the patients who performed these tests, the majority had tumors with negative hormone receptors, a high Ki 67 index, and overexpressed HER2. The role of these various factors in prognosis is also well known. Indeed the metastatic relapses are more common in the first 5 years, when the initial tumor is negative $\mathrm{RH}$, high $\mathrm{Ki} 67$ index, and overexpressed HER2 [19]-[25]. 
Table 2. Distribution of patients according to the characteristics of the initial tumor.

\begin{tabular}{|c|c|c|}
\hline Characteristic of the initial tumor & Population & Frequency (\%) \\
\hline \multicolumn{3}{|l|}{ Histological type } \\
\hline - Invasive ductal & 122 & 68.5 \\
\hline - Invasive lobular & 56 & 31.4 \\
\hline - Total & 178 & 100 \\
\hline \multicolumn{3}{|l|}{ Clinical stage } \\
\hline$-\mathrm{I}$ & 25 & 14 \\
\hline- II & 68 & 38.2 \\
\hline - III & 85 & 47.8 \\
\hline - Total & 178 & 100 \\
\hline \multicolumn{3}{|l|}{ Grade SBR } \\
\hline$-\mathrm{I}$ & 31 & 17.4 \\
\hline- II & 63 & 35.4 \\
\hline - III & 84 & 47.2 \\
\hline - Total & 178 & 100 \\
\hline \multicolumn{3}{|l|}{ Ki 67} \\
\hline - Low & 8 & 13.8 \\
\hline - Middle & 23 & 39.7 \\
\hline - High & 27 & 46.5 \\
\hline - Total & 58 & 100 \\
\hline \multicolumn{3}{|l|}{ Hormonal status } \\
\hline - Positive & 12 & 20.7 \\
\hline - Negative & 46 & 79.3 \\
\hline - Total & 58 & 100 \\
\hline \multicolumn{3}{|l|}{ HER2 } \\
\hline - Positive & 21 & 42 \\
\hline - Negative & 37 & 58 \\
\hline - Total & 58 & 100 \\
\hline
\end{tabular}

\subsection{Characteristics of Metastases}

\section{- Sitesof metastases}

Table 3 shows that majority of metastases observed in the patients were unique (62.9\%), affecting mainly the bones (36.6\%), the lung (25\%) the liver (17\%), and the brain (10\%)., 7\%). Several authors have also highlighted the high frequency of bone and then pulmonary forms [26] [27]. As for Anhoux [28], he found in a study conducted in this ivoirian context that the most frequent forms were pulmonary and hepatic.

But some authors think that it is premature to conclude at preferential sites in africanconditions due to an underestimation linked to insufficiency of the para- 
clinical explorations: MRI, PET scan (positron emission tomography) [28] [29].

- Chronology of occurrence of metastases

After initial treatment of patients, metastases occurred within an average time of 2.4 years and the cumulative rate of metastasis was $76.5 \%$ at 3 years and $95.4 \%$ at 5 years. It is recognized that the majority of metastases occur in the first 5 years (Table 4), justifying an increased surveillance during this period [3] [5] [13].

However, rare cases of belated metastases occurring beyond 20 years have been reported, requiring also a long-term monitoring of all patients operated of breast cancer [3] [30] [31].

\section{- Survival after metastatic relapse}

Mortality after metastatic relapse was high and early in the study: the cumulative

Table 3. Distribution of patients according to the characteristics of their metastasis.

\begin{tabular}{ccc}
\hline Characteristics of metastases & Population & Frequency (\%) \\
\hline Sites: & & \\
- Unique & & \\
- Bones & 41 & 36.6 \\
- Lung & 28 & 25 \\
- Liver & 19 & 17 \\
- Brain & 12 & 10.7 \\
- Hollow viscera & 9 & 8 \\
- Peritoneum & 3 & 2.7 \\
- Total & 112 & 100 \\
- Multiple & & \\
- Bones + Lung & & 42.4 \\
- Bones + Liver & 28 & 34.8 \\
- Brain + Liver & 23 & 15.2 \\
- Multiple sites & 10 & 7.6 \\
- Total & 5 & 100
\end{tabular}

Table 4. Distribution of patient according to the chronology of occurrence of metastases.

\begin{tabular}{cccc}
\hline Chronology of occurrence of metastases & population & Frequency (\%) & Cumulative frequency (\%) \\
\hline$-<1$ yr & 25 & 14 & 14 \\
-12 years & 59 & 33.1 & 47.1 \\
-23 years & 53 & 29.8 & 76.9 \\
-34 years old & 12 & 6.8 & 83.7 \\
-45 years old & 21 & 11.8 & 95.4 \\
$-5-6$ years & 00 & 00 & 95.4 \\
$-6-7$ years & 8 & 4.5 & 100 \\
Total & 178 & 100 & \\
\hline
\end{tabular}




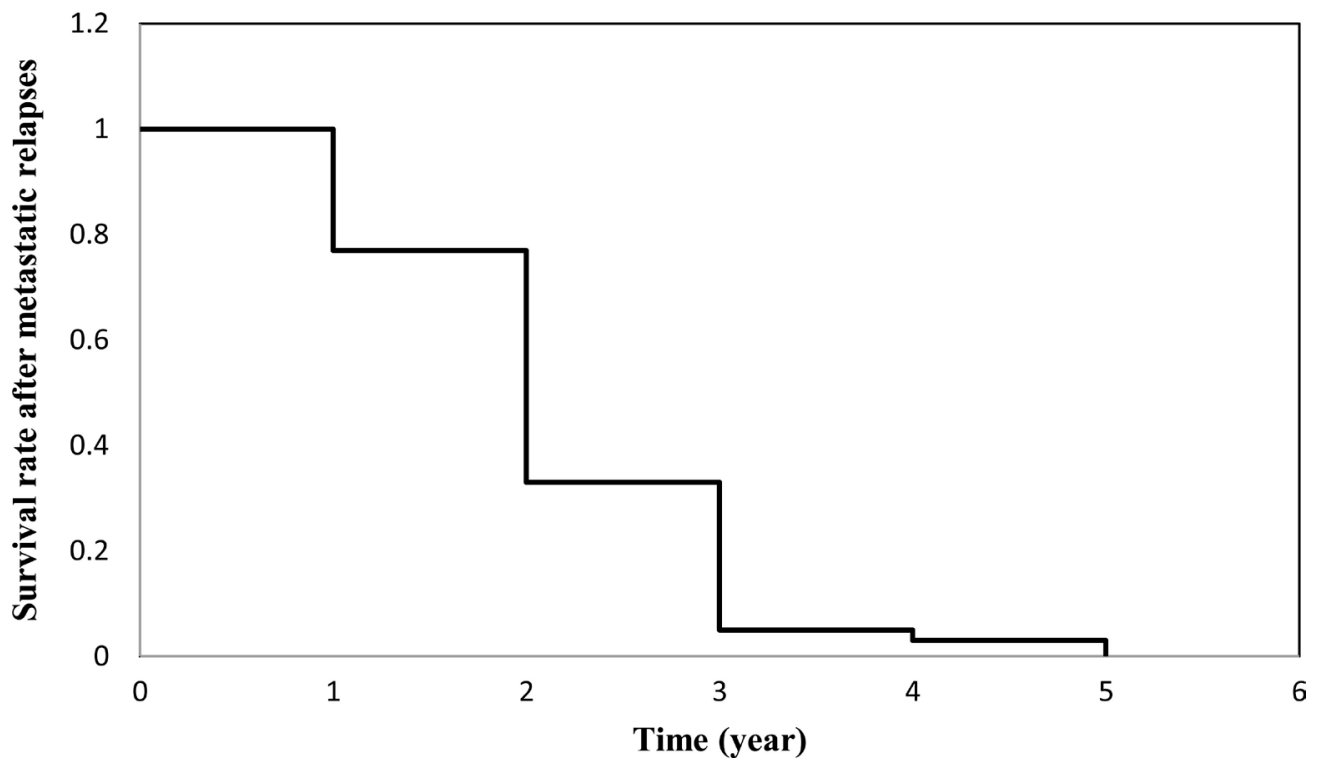

Figure 2. Patient survival curve after metastatic relapses.

survival rate was $5 \%$ at 3 years and nil at 5 years (Figure 2). In general, the survival rate varies according to the number and the site of the metastases, but also to the quality of the management. Thus, in developed countries, survival after metastatic relapse in patients operated for locally advanced breast cancers is higher than in developing countries, ranging from $30 \%$ to $50 \%$ at 5 years and $25 \%$ at 10 years [8]. It should be noted that in the countries with limited equipment the treatment of primary tumors and metastatic relapses remains incomplete, darkening the prognosis. Indeed, radiotherapy is not available in the subsaharan african countries, and the latest generation molecules such as monoclonal antibodies or targeted therapy are too costly for their population.

\section{Conclusion}

This study showed that the management of breast cancers was delayed in the ivoirian context and resulted in a high frequency of metastatic relapses. These metastases occurred early and were responsible for a high and rapid mortality. In order to improve the survival of breast cancer patients, we must therefore focus on the establishment of screening and early diagnosis programs in these developing countries.

\section{References}

[1] Toure, M., Nguessan, E., Bambara, A.T., Kouassi, Y.K.K., Dia, J.M.L. and Adoubi, I. (2013) Factors Linked to Late Diagnosis in Breast Cancer in Sub-Saharan Africa: Case of Cote D'Ivoire. Gynécologie Obstétrique et Fertilité, 41, 696-700. https://doi.org/10.1016/j.gyobfe.2013.08.019

[2] Ferlay, J., Soerjomataram, I., Ervik, M., Dikshit, R., Eser, S., Mathers, C., Rebelo, M., Parkin, D.M., Forman, D. and Bray, F. (2013) GLOBOCAN 2012 v1.0, Cancer Incidence and Mortality Worldwide: IARC CancerBase No. 11. http://globocan.iarc.fr

[3] American Society of Clinical Oncology (1999) Update of Recommended Breast 
Cancer Surveillance Guidelines. Journal of Clinical Oncology, 17, 1080-1082.

[4] Sebban, E. (2006) Pour La Surveillance Intensive Après Traitement Du Cancer Du Sein. Gynécologie Obstétrique et Fertilité, 34, 268-270.

https://doi.org/10.1016/j.gyobfe.2006.01.023

[5] Kamby, C. (1990) The Pattern of Metastases in Human Breast Cancer: Methodological Aspects and Influence of Prognostic Factors. Cancer Treatment Reviews, 17, 37-61. https://doi.org/10.1016/0305-7372(90)90075-Q

[6] Aukema, T.S., Russell, N.S., Wesseling, J. and Rutgers, E.J. (2009) Extensive Soft Tissue Resection with Autologous Tissue Closure for Locally Recurrent Breast Cancer: Lasting Local Control and Acceptable Morbidity. European Journal of Surgical Oncology (EJSO), 35, 469-474. https://doi.org/10.1016/j.ejso.2008.12.015

[7] Berenice, Q. (2014) Cancer du sein localement avancé: Facteurs prédictifs de mastectomie après chimiothérapie neoadjuvante. A propos d'une série rétrospective de 247 patientes traitées à l'Institut Bergonié. Médecine Humaine Et Pathologie, 1-85.

[8] Early Breast Cancer Trialist'Collaborative Group (2006) Effects of Radiotherapy and of Differences in the Extent of Surgery for Early Breast Cancer on Local Recurrence and 15 Year Survival: An Overview on the Randomized Trials. Lancet, 366, $2087-$ 2106.

[9] Chevallier, B., Heintzman, F. and Mosseri, V. (1989) Quels sont les facteurs pronostics du cancer du sein opérable sans envahissement ganglionnaire axillaire histologique? Résultats d'une analyse uni et multifactorielle. Bulletin Du Cancer, 76, 51-60.

[10] De La Rochefordière, A., Asslain, B. and Campana, F. (1993) Age prognostic factor in premenopausal breast carcinoma. Lancet, 341, 1039-1043. https://doi.org/10.1016/0140-6736(93)92407-K

[11] Guié, P., Dia, J.M., Saki, C., Bohoussou, E., Nguessan, E., Yao, I., et al. (2013) Dépistage des cancers du col de l'utérus et du sein: connaissances et attitudes des femmes fonctionnaires vues en consultation au CHUT. Revue Medicale De Liege, 15, 141-145.

[12] Belghiti, L., Chenguiti-ansari, A. and Elaanine, M. (2002) Facteur pronostic dans le cancer du sein. Espérance Médicale, 9.

[13] Lansac, J. and Diouf, A. (1998) La surveillance d'une femme traitée pour cancer du sein. Journal de Gynécologie Obstétrique et Biologie de la Reproduction, 27, 21-23.

[14] Nemoto, T., Vana, J. and Bedwani, R.N. (1980) Management and Survival of Female Breast Cancer: Results of a National Survey by the American College of Surgeons. Cancer, 45, 2917-2924.

https://doi.org/10.1002/1097-0142(19800615)45:12<2917::AID-CNCR2820451203> 3.0.CO;2-M

[15] Koscielny, S., Tubiana, M. and Lê, M.G. (1984) Breast Cancer: Relationship between the Size of the Primary Tumour and the Probability of Metastatic Dissemination. British Journal of Cancer, 49, 709-715. https://doi.org/10.1038/bjc.1984.112

[16] Spielmann, M., Riofrio, M. and Zelek, L. (2000) Facteurs pronostiques du cancer du sein et facteurs prédictifs de la réponse au traitement. La Lettre du Cancérologue, 9 , 29-35.

[17] Treilleux, I. and Brémond, A. (2002) Pronostic des cancers du sein. Encyclopédie médico-chirurgicale, 865, 1-7.

[18] Contesso, G., Mouriesse, H. and Friedman, S. (1987) The Importance of Histologic Grade in Long-Term Prognosis of Breast Cancer: A Study of 1,010 Patients, Uniformly Treated at the Institut Gustave-Roussy. Journal of Clinical Oncology, 5, 1378-1386. https://doi.org/10.1200/JCO.1987.5.9.1378 
[19] Hortobagyi, G.N., Kau, S.-W. and Buzdar, A.U. (2004) What Is the Prognosis of Patients with Operable Breast Cancer Five Years after Diagnosis? Proceedings of the American Society of Clinical Oncology, Los Angeles, 5-8 June 2004.

[20] Fisher, B., Redmond, C., Fisher, E.R. and Caplan, R. (1988) Relative Work of Estrogen or Progesterone Receptor and Pathologic Characteristics of Differentiation As Indicators of Prognosis in Node Negative Breast Cancer Patients: Findings from the National Surgical Adjuvant Breast and Bowel Project Protocol B-06. Journal of Clinical Oncology, 6, 1076-87. https://doi.org/10.1200/JCO.1988.6.7.1076

[21] Dowseet, M., Nielsen, T.O., A’Hern, R., Bartlett, J., Coombes, R.C., Cuzick, J., et al. (2011) Assessment of Ki 67 in Breast Cancer: Recommendation from the International in Breast Cancer Working Group. Journal of the National Cancer Institute, 103, 1656-1664. https://doi.org/10.1093/jnci/djr393

[22] Nieto, Y., Nawaz, S. and Cagnoni, P.J. (1999) Overexpression of Her 2/Neu (H2N), but Not P53 Mutations Is a Poor Prognostic Factor of High-Risk Primary Breast Cancer (HRPBC) Treated With High-Dose Chemotherapy (HDC) and Autologous Stem-Cell Transplant (ASCT). Proceedings of the American Society of Clinical Oncology.

[23] Siegel, R.S., Kothary, N. and Johnson M. (1999) Analysis of 512 Breast Cancer in Which Her-2/Neu Assessment Was Performed. Proceedings of the American Society of Clinical Oncology.

[24] Gancberg, D., Lespagnard, L., Rouas, G., et al. (1999) Routine Evaluation of Her-2/Neu Amplification and Overexpression in Breast Cancer: Correlation with Grade, Proliferation and E-Cadherin Expression. Proceedings of the American Society of Clinical Oncology.

[25] Wolff, A.C., Hammond, M.E., Hicks, D.G. and Dowseet, M. (2013) Recommendations for Human Epiderma Growth Factor Receptor 2 Testing in Breast Cancer: American Society of Clinical Oncology/ College of American Pathologists Clinical Practice Guideline Update. Journal of Clinical Oncology, 31, 3997-4013. https://doi.org/10.1200/JCO.2013.50.9984

[26] Ferrero, J.M., Pivot, X. and Namer, M. (1995) Association Mitoxantrone-Vinorelbine en première ligne thérapeutique dans le cancer du sein métastatique. Bulletin Du Cancer, 82, 2002-2007.

[27] Renaud, R., Gairard, B. and Bellocq, J.P. (1991) Le risque de métastases à distance In Cancer du sein: surveillance après traitement. BREMOND A. Médition, 16-26.

[28] Anhoux, A., Adoubi, I. and Echimane, K.A. (2002) Sites métastatiques du cancer du sein de la femme noire en Côte d'Ivoire. Espérance Médicale, 9, 622-625.

[29] Harouna, D.Y., Boukary, I. and Kanou, H.M. (2002) Le cancer du sein de la femme au Niger. Medecine d'Afrique Noire, 1, 39-43.

[30] Mamby, C.C., Love, R.R. and Heaney, E. (1993) Metastatic Breast Cancer 39 Years after Primary Treatment. Wisconsin State Journal, 92, 567-569.

[31] Tueche, S.G., Nguyen, H., Larsimont, D. and Andry, G. (1999) Late Onset of Tonsillar Metastasis from Breast Cancer. European Journal of Surgical Oncology. 25, 439-448. https://doi.org/10.1053/ejso.1999.0672 
Submit or recommend next manuscript to SCIRP and we will provide best service for you:

Accepting pre-submission inquiries through Email, Facebook, LinkedIn, Twitter, etc. A wide selection of journals (inclusive of 9 subjects, more than 200 journals)

Providing 24-hour high-quality service

User-friendly online submission system

Fair and swift peer-review system

Efficient typesetting and proofreading procedure

Display of the result of downloads and visits, as well as the number of cited articles Maximum dissemination of your research work

Submit your manuscript at: http://papersubmission.scirp.org/

Or contact ojog@scirp.org 